\title{
Psicólogo e escola: a compreensão de estudantes do ensino fundamental sobre esta relação
}

\author{
Izabella Mendes Sant'Ana \\ Antonio Euzébios Filho \\ Fernando Lacerda Junior \\ Raquel Souza Lobo Guzzo
}

\section{Resumo}

Este estudo visou compreender como alunos do Ensino Fundamental de uma escola pública municipal de Campinas percebiam o papel do psicólogo na escola. As informações foram obtidas por meio de desenhos e escrita para 127 alunos de $1^{\text {a }}$ a $4^{\mathrm{a}}$ séries e de respostas a duas perguntas sobre a atuação do psicólogo para 113 alunos de $5^{\mathrm{a}}$ a $8^{\mathrm{a}}$ séries. Os resultados apontaram que, em geral, os alunos perceberam o psicólogo como um profissional que conversa sobre a vida e fornece apoio à comunidade escolar, atuando como mediador nas interações sociais ocorridas nesse contexto. As expectativas dos alunos de $5^{\mathrm{a}}$ a $8^{\mathrm{a}}$ séries acerca do trabalho do psicólogo envolveram: orientação, ajuda à escola e seus agentes na resolução de problemas e participação ativa no cotidiano escolar. Foi evidenciada uma tendência positiva quanto à inserção do psicólogo na escola na visão dos estudantes, mesmo com limitações na compreensão do seu papel.

Palavras-chave: Psicologia escolar, estudantes de $1^{\circ}$. grau, psicológos escolares.

\section{The psychologist and the school: the understanding of Elementary school students on this relation}

\begin{abstract}
This study investigates how students from an Elementary public school in Campinas, São Paulo, Brazil, perceived the psychologist's role at school. The information was obtained from drawings and writings carried out by 127 students in their initial grades, besides 113 students in their final grades answered two questions about the work of the psychologist. The results indicated that in general students perceived the psychologist as a professional who talks about the aspects of () life and gives support to the school community, acting as a mediator of the social interactions in this context. The final-grade students' expectations about the work of the psychologist involved: guidance, help to school and their members to solve problems and active participation in school daily life. The results showed a positive tendency towards the inclusion of a psychologist in school, according to students, despite the limited understanding of her or his role.
\end{abstract}

Keywords: school psychology, elementary school students, school psychologists.

\section{Psicólogo y escuela: comprensión de los estudiantes de enseñanza primaria sobre esta relación}

\begin{abstract}
Resumen
Este estudio buscó comprender cómo los alumnos de la enseñanza primaria de una escuela municipal de la ciudad de Campinas percibían el rol del psicólogo en la escuela. Las informaciones se obtuvieron por medio de dibujos y textos escritos para 127 alumnos de 1 er a 4 to año y de respuestas a dos preguntas sobre la actuación del psicólogo para 113 alumnos de 5to a 8vo año. Los resultados señalaron que, en general, los alumnos percibieron al psicólogo como un profesional que conversa sobre la vida y proporciona apoyo a la comunidad escolar, actuando como mediador en las interacciones sociales que se dan en este contexto. Las expectativas de los alumnos de 5to a 8vo año acerca del trabajo del psicólogo abarcaron: orientación, ayuda a la escuela y sus agentes en la solución de problemas y participación activa del cotidiano escolar. Se evidenció una tendencia positiva en relación a la inserción del psicólogo en la escuela desde el punto de vista de los estudiantes, inclusive con las limitaciones en la comprensión de su rol.
\end{abstract}

Palabras-clave: psicología escolar, estudiantes de primaria, psicólogo escolar. 


\section{Introdução}

A literatura nacional e internacional acerca da atuação do psicólogo escolar é extensa e tem focalizado, dentre outros aspectos, a delimitação do campo de ação desse profissional. Em geral, estudos brasileiros têm abordado as atividades realizadas pelo psicólogo que atua no contexto educacional, identificando as formas de trabalho e sua inserção junto às instituições escolares. Algumas destas investigações têm considerado as opiniões de psicólogos (Neves, 1989; Senna \& Almeida, 2005), pais (Caetano, 1992) professores e outros profissionais que participam do âmbito educacional (Escudero, Martinez, Sawaya, Duarte, \& Campos, 1996; Rossi, 1998; Silva, 1995). No entanto, a visão de alunos ainda é pouco focalizada nas pesquisas nacionais.

Algumas pesquisas (Caetano, 1992; Neves, 1989; Silva, 1995) indicam a existência de uma representação social do psicólogo, o identificando como um profissional que exerce as funções de ajuda e orientação.

Em um estudo envolvendo psicólogos de escolas públicas da Prefeitura de São Paulo, Neves (1989) apontou que, embora esses profissionais tenham clareza da importância da atuação preventiva, as atividades mais frequentemente indicadas por eles foram o encaminhamento de alunos e a orientação aos pais.

Nesse sentido, a visão predominante do profissional de psicologia aplicado à educação ainda é, tal como já se destacou no passado (Ribeiro \& Guzzo, 1987), a de um profissional que atua na identificação e resolução de problemas emocionais, de comportamento ou de aprendizagem, ou seja, um modelo de intervenção pautado em uma perspectiva clínica.

Caetano (1992) investigou as representações de pais de alunos sobre a atuação do psicólogo na escola e ressaltou que os pais atribuem importância ao trabalho desse profissional nesse contexto. O psicólogo escolar é visto como um profissional que tem formação específica a qual the permite orientar alunos e pais, além de tratar de inúmeras questões referentes ao desenvolvimento humano, todavia, os participantes também apontaram falhas na atuação do profissional que da área.

Em um estudo realizado por Silva (1995), o profissional de psicologia foi percebido pelos agentes educacionais como um profissional associado à figura de apoio, do amigo e confidente, sendo vinculado às idéias de empatia, solidariedade e sigilo. Segundo os entrevistados, caberia a este profissional realizar atividades de atendimento individual ao aluno, palestras e trabalhos de grupo com alunos, ações direcionadas aos professores, orientação vocacional e encaminhamentos. A autora concluiu, entre outros aspectos, que o trabalho do psicólogo foi visto como remediativo, embora seja evidenciada a perspectiva da atuação preventiva, estando voltada, principalmente, para o aluno com ou sem problema.

Resultados semelhantes foram encontrados por Escudero e cols. (1996) e Rossi (1998), enfocando também a necessidade desse profissional avaliar e elaborar psicodiagnósticos dos alunos, intervir em problemas disciplinares e de aprendizagem, fornecer orientações aos educadores e favorecer a relação professor-aluno.

Durante várias décadas, a atuação do psicólogo escolar esteve limitada à avaliação e ao diagnóstico de crianças nas instituições de ensino, porém, nos últimos anos, este papel vem sendo criticado, sugerindo outras propostas de atividades exercidas pelo psicólogo, nacional e internacionalmente. Pode-se notar o surgimento de atuações de caráter preventivo, comunitário e envolvendo grupos para toda a comunidade escolar (Guzzo, Martínez, \& Campos, 2007; Guzzo \& Wechsler, 1993; Oakland \& Sternberg, 1993;).

Esta mudança no perfil predominante da atuação na escola é destacada em pesquisas mais atuais. Em estudo recente com psicólogos que atuam na rede pública do Distrito Federal, Senna e Almeida (2005) destacam a ampliação do campo de atuação na escola, assim como a superação de modelos tradicionais que se fundamentam em teorias individualistas e a-históricas. As autoras ressaltam que as atividades predominantes dos participantes da pesquisa concentram-se no atendimento ao aluno, ao professor, à equipe profissional e aos familiares, além outras atividades mais novas como o atendimento à direção e a implementação de projetos alternativos envolvendo pais e mesmo a comunidade na escola, compreendendo a importância de vários processos na dinâmica escolar que afetam o desenvolvimento das crianças.

O mesmo é apontado por Cruces (2005) o qual, pesquisando a atuação de egressos que atuam em psicologia escolar em São Paulo, conclui que há predominância de atividades interdisciplinares e envolvendo grupos, ao invés de atividades focadas somente no aluno ou na família, isto é, o psicólogo passa a atuar mais enquanto um mediador em diferentes atividades envolvendo o conjunto dos segmentos que atuam na escola.

Em síntese, pode-se dizer que, dentre as perspectivas de atuação para esse profissional na área educacional, encontram-se: a) o fornecimento de assessoria na elaboração, implementação e avaliação de programas especiais de ensino, do projeto político pedagógico e de programas direcionados aos pais; b) ações voltadas à melhoria das relações funcionais entre os vários segmentos da escola; c) realização de treinamento e desenvolvimento técnico-profissional de educadores; d) apoio aos professores, alunos e instituições escolares em questões relativas ao desenvolvimento humano; e e) programas de prevenção. O papel da pesquisa também tem sido reiterado como essencial, na medida em que fornece informações importantes que podem orientar práticas para intervenção na realidade (Del Prette, 1999; Guzzo, 1999; Guzzo cols., 2007; Witter, 1999).

Pode-se relacionar o surgimento de novas práticas para o psicólogo escolar com os questionamentos sobre seu papel e função dentro das instituições educativas. Alguns autores têm apontado a necessidade de que este profissional 
supere o modelo médico de atuação que atribui à criança e sua família a responsabilidade pela experiência de fracasso na escola, passando a nortear suas ações pelo compromisso de transformação do contexto educativo visando a um efetivo processo de democratização educacional e social (Guzzo et al., 2007; Patto, 1984; Tanamachi, Proença, \& Rocha, 2000;). Outros, a partir destas críticas, têm apontado competências e habilidades necessárias ao exercício profissional pautados no compromisso ético, político e social com a realidade brasileira (Almeida, 2003; Araujo \& Almeida, 2005; Guzzo, 1999).

As implicações para a profissão ao assumir o compromisso com os problemas vividos pela maioria da população latino-americana podem ser pensadas a partir das contribuições de Martín-Baró (1997, 1998, 2000) sobre o caráter político da Psicologia. Segundo o autor, o maior desafio para o psicólogo não se reduz a pensar sobre os problemas que a grande parte da população enfrenta, mas buscar contribuir para transformar uma realidade de opressão e dominação a que estas pessoas estão submetidas.

Os psicólogos tradicionais agem na realidade no sentido de legitimar a manutenção da ordem e o status quo. No contexto escolar, a psicologia dominante difundiu-se enquanto uma ação individualista que se centra na análise das dificuldades de aprendizagem do aluno, como se este fosse um problema meramente decorrente da incapacidade do aluno "absorver" o conhecimento que the é transferido (Patto, 1984, 1993, 1997).

Essa incapacidade do aluno tem se transformado em argumento para justificar a superioridade intelectual da elite sobre as classes subalternas. Segundo Patto (1984, 1993, 1997) , a culpabilização do aluno pelo fracasso escolar exerce impacto na vida das crianças e adolescentes pobres, na medida em que as dificuldades nos estudos passam a ser associadas à própria condição de pobreza.

A manutenção das práticas tradicionais de atuação do psicólogo escolar contribui para fortalecer e difundir uma análise individualizada de problemas de ordem social como a aprendizagem. Não por acaso, muitos psicólogos escolares têm focalizado sua atenção no aluno, sem levar em conta a importância do trabalho com professores, funcionários, pais e com a comunidade no entorno da escola.

Neste sentido pode-se ressaltar que a ação do psicólogo escolar deve ser ampla, estabelecida junto à comunidade e no sentido de desmistificar o conceito de "carência cultural", o preconceito em relação à maioria da população, a dicotomia pedagógico versus psicológico e uma visão descontextualizada que desconsidera o sujeito (Patto, 1984,1997).

Para Guzzo (2005), a prática do psicólogo escolar deve estar fundamentada em um princípio básico: a autonomia. A autonomia compreendida em sua forma política, a partir do referencial da pedagogia da libertação de Freire (1973, 1989, 2006) que se manifesta por meio de um processo de reflexão crítica sobre a realidade, o cotidiano da escola e dos seus agentes. A autonomia, como uma dimensão do processo de desenvolvimento humano, estabelece para o psicólogo a necessidade de se conhecer o aluno, a expressão de sentimentos como forma de conhecer o sujeito que se expressa por meio do diálogo entre os diferentes agentes da escola (Guzzo, 2005).

Frente às várias perspectivas sobre a atuação psicológica no âmbito educativo, torna-se relevante compreender como a comunidade escolar, em especial estudantes do ensino fundamental de $1^{\mathrm{a}}$ a $8^{\mathrm{a}}$ séries percebe o papel do psicólogo nesse contexto. Por isso, o presente estudo buscou conhecer o que pensam estudantes do Ensino Fundamental de uma escola pública da rede municipal de Campinas sobre o psicólogo na escola.

\section{Método}

\section{Participantes}

Participaram desta pesquisa 240 estudantes do Ensino Fundamental de uma escola pública municipal de Campinas, sendo 127 alunos de $1^{\mathrm{a}}$ a $4^{\mathrm{a}}$ séries com idades entre 7 a 12 anos e 113 alunos de $5^{\mathrm{a}}$ a $8^{\mathrm{a}}$ séries com idades entre 11 a 17 anos.

\section{Material}

Diante da dificuldade para obter informações escritas para os diferentes segmentos de estudantes, foram utilizadas duas formas diferentes para acessar a visão dos estudantes sobre o profissional de psicologia: para as turmas de $1^{\text {a }}$ à $4^{\text {a }}$ série, foram utilizados materiais disponíveis nas próprias atividades de sala de aula: lápis de cor e papel sulfite para os desenhos, enquanto para as demais turmas utilizou-se um roteiro com duas questões: (1) O que você acha que o psicólogo faz?; (2) O que você espera que o psicólogo faça na escola? ${ }^{3}$

\section{Procedimentos}

Esta pesquisa faz parte de um projeto denominado "Do Risco à Proteção: uma intervenção preventiva na comunidade", que está sendo realizado nessa instituição de ensino há três anos. Esse projeto visa identificar os fatores de risco e proteção ao desenvolvimento de crianças de comunidades de baixa renda, buscando favorecer a conscientização de crianças, pais, professores e profissionais acerca da realidade em que vivem, isto é, de suas condições de vida, a fim de promover uma maior mobilização e participação dos indivíduos da comunidade mediante o fortalecimento das redes sociais de apoio.

Esse projeto foi aprovado pelo Conselho da escola (representado por alunos, pais, funcionários, equipe de gestão e professores) e a direção assinou o termo de consentimento livre e esclarecido contendo os objetivos e as

3 Utilizou-se também um termo de consentimento informado, contendo os objetivos e explicitando outras normas éticas da pesquisa, redigido de acordo com a Resolução de dezembro de 2000 do Conselho Federal de Psicologia e o que dispõe a Lei Nacional sobre a Pesquisa com seres humanos. O projeto foi aprovado pelo Comitê de Ética da PUC Campinas. 
normas éticas da pesquisa, autorizando, assim, a realização de estudos nesta unidade de ensino.

Os alunos realizaram as atividades nas salas de aula. Para os alunos de $1^{\mathrm{a}}$ a $4^{\mathrm{a}}$ séries, foi pedido eles desenhassem e escrevessem o que achavam que o psicólogo faz na escola. Algumas vezes foi necessário registrar o relato da criança sobre o desenho no verso dos mesmos. Assim sendo, o desenho serviu como mediação na conversa da criança com o psicólogo e a análise focalizou o que foi verbalizado pelos alunos e não o desenho propriamente dito. Para os alunos de $5^{\mathrm{a}}$ a $8^{\mathrm{a}}$ séries, as três questões eram escritas na lousa da sala de aula e, após explicar os objetivos da atividade, solicitouse que respondessem a todas as questões. Quando algum aluno apresentava dificuldades para redigir respostas, algum membro da equipe o auxiliava ou, em alguns casos, fazia o registro a partir do seu relato. No entanto, a maior parte dos questionários foi respondida pelos próprios alunos.

\section{Resultados e Discussões}

\section{Ensino Fundamental I: $1^{\mathrm{a}}$ a $4^{\mathrm{a}}$ séries}

As informações obtidas foram analisadas segundo análise de conteúdo (Jacques, 1993). Em relação aos dados referentes aos alunos de $1^{a}$ a $4^{a}$ séries, foram identificadas cinco categorias a partir dos registros (especificamente às informações escritas sobre os desenhos dos alunos) a respeito do papel do psicólogo na escola, a saber:

1. Conversa sobre a vida: opiniões dos alunos que fazem referência ao psicólogo como um profissional que conversa com docentes, pais e alunos sobre diferentes questões do cotidiano, da escola e/ou da vida das pessoas. Ex: "Conversa com as mães, pais, professoras e filhos".

2. Ajuda quando existem problemas: expressões acerca do papel do psicólogo em que caberia a este profissional auxiliar as pessoas na presença de problemas, de caráter pessoal e/ou familiar, bem como nas dificuldades escolares. Ex: "Convers, com as crianças tristes". "O psicólogo ajuda as crianças é muito legal eles ajuda as crianças que têm dificuldades para lê e escrever".

3. Orienta sobre situacõos específicas: opiniões que apontam diferentes formas de orientação dadas pelo psicólogo escolar. Ex: "A psicóloga conversa com os alunos, ensina que não é para brigar, ensina coisas boas. Eu gosto das psicólogas porque quando eu brigo ou machuco, elas falam comigo e me levam no posto".

4. Papel de professor: visões do psicólogo como um profissional que realiza as mesmas tarefas de um professor, isto é, ensina aos alunos os conteúdos escolares. Ex: "Ensina os alunos que não sabem ler e escrever".

5. Atribuições relativas a outras profissões: indicações de tarefas ou papéis de outras profissões que não competem ao psicólogo escolar. Ex: "Trabalha na biblioteca e na secretaria".

Em relação às opiniões de alunos das séries iniciais do ensino fundamental, pôde-se verificar que $48 \%$ das
Tabela 1. Distribuição das categorias de respostas de alunos de $1^{a}$ a $4^{\mathrm{a}}$ séries sobre o papel do psicólogo na escola

\begin{tabular}{lcc}
\hline Categorias de respostas & N & $\%$ \\
\hline Conversa sobre a vida & 61 & 48 \\
Ajuda quando existem problemas & 36 & 28 \\
Orienta sobre situações específicas & 11 & 9 \\
Visão positiva do psicólogo & 9 & 7 \\
Papel de professor & 6 & 5 \\
Atribuições relativas a outras profissões & 4 & 3 \\
\hline Total & 127 & 100 \\
\hline
\end{tabular}

Fonte: Elaboração dos autores

respostas consideraram o psicólogo como o profissional que realiza conversas com alunos e demais participantes da comunidade escolar a respeito de vários aspectos da vida, tais como relações estabelecidas na escola, na família e no contexto comunitário, conforme apresentado na Tabela 1.

O psicólogo foi considerado como um profissional que fornece ajuda às pessoas na presença de problemas psicossociais ou de aprendizagem em $28 \%$ das respostas. Outras categorias referem-se a este profissional com um papel de orientador em relação a várias situações do cotidiano ou da vida das pessoas (9\%), sendo sua atuação considerada importante no meio escolar em $7 \%$ das considerações.

Os resultados indicam que, para as crianças das séries iniciais do ensino fundamental, o psicólogo escolar é visto como um profissional que conversa sobre diversos aspectos da vida. Possivelmente, esta visão está relacionada à experiência atual dos alunos com a equipe do serviço de psicologia presente na escola. O contato dos alunos com a equipe ocorreu semanalmente e as ações realizadas envolveram, dentre outros aspectos, conversas individuais e em grupo com os alunos em diferentes espaços da escola, em ambientes reservados ou em salas de aula e nos intervalos do recreio dos alunos.

Nesse sentido, os resultados indicaram que, para a maioria dos alunos de faixa etária entre sete aos doze anos, o diálogo constitui-se como principal aspecto do papel do psicólogo na escola, não sendo focalizadas neste estudo funções específicas desse profissional, como: orientação a professores e funcionários, desenvolvimento de programas para pais, entre outras, como apontam os estudos de Del Prette (1999), Escudero e cols. (1996) e Rossi (1998). Assim, torna-se necessária a discussão com os alunos sobre as possibilidades de atuação psicológica no espaço escolar.

Os alunos também focalizaram o psicólogo como um profissional que colabora na resolução de problemas. Tal aspecto tem sido freqüentemente apontado em várias pesquisas (Caetano, 1992; Rossi, 1998; Silva, 1995; entre outras) que destacam a necessidade do psicólogo escolar favorecer o processo ensino-aprendizagem, mas 
fazem críticas a perspectiva do trabalho psicológico estar associado, principalmente, à intervenção com os chamados "alunos-problema".

Opapeldo psicólogoassemelhando-seao professorfoi indicado em $5 \%$ das manifestações e de outros profissionais em $3 \%$ como, por exemplo, de um médico, o que reafirma a necessidade de fornecer informações e esclarecimentos aos alunos acerca das ações que são pertinentes à prática desse profissional no âmbito educativo.

Ademais, cabe salientar que a presença do psicólogo na escola é percebida como positiva em $7 \%$ das considerações dos alunos de $1^{\text {a }}$ a $4^{\text {a }}$ séries que foram ouvidos, o que parece confirmar as informações apontadas no estudo de Silva (1995), no qual o psicólogo é associado à figura de apoio e do amigo, estando vinculado às idéias de empatia e solidariedade.

\section{Ensino Fundamental II: $5^{\mathrm{a}}$ à $8^{\mathrm{a}}$ série}

No processo de análise dos resultados, verificou-se que uma parte dos alunos elaborou apenas uma resposta em relação às duas questões. Assim, decidiu-se criar categorias e utilizá-las de acordo com o conteúdo das respostas em sua correspondência aos temas abordados nas questões 1 e 2 do roteiro utilizado. As respostas foram, portanto, analisadas em função de categorias de sentido expressas nas tabelas 2 e 3 tendo sido excluídas da análise respostas que não se relacionavam ao conteúdo solicitado ou em branco.

No que concerne à primeira questão - a visão dos alunos sobre o trabalho do psicólogo observou-se que vários alunos fizeram avaliações de caráter geral sem atribuir alguma função específica a este profissional. Apesar deste fato, foram identificadas seis categorias nas respostas dadas:

1. Desvio de função: refere-se a atividades em que os alunos definiram funções do psicólogo a partir de estereótipos difundidos pela sociedade nos quais há exageros sobre suas capacidades ou certa simplificação de suas responsabilidades. Ex: "Ler a mente", "Médico de loucos".

2. Orienta, ajuda e conversa: respostas quefocalizaram ações do psicólogo envolvendo o diálogo que, muitas vezes, serve para aconselhar, orientar etc. Ex: "Conversar com as pessoas", "Ajudar mesmo sem ter problemas".

3. Avaliação positiva: aspectos ressaltados pelos alunos que denotam uma avaliação positiva tanto do profissional como do trabalho do psicólogo, mas sem especificar ações específicas deste profissional. Ex. "Todas as escolas deveriam ter", "Trabalho muito interessante".

4. Avaliação negativa: respostas que caracterizam uma avaliação negativa do psicólogo, isto é, visões que não atribuem importância à ação do psicólogo. Ex. "Só faz perguntas e não faz nada".

5. Muda comportamentos: referências à intervenção do psicólogo na tentativa de modificar comportamentos (normalmente considerados negativos) por meio da orientação/ensino. Ex. "Ensinar a ser menos violento", "Não brigar e ensinar os outros a se acalmar".
6. Não sabe: respostas em que os alunos apontavam não conhecer o papel do psicólogo.

A Tabela 2 apresenta as categorias relativas à opinião dos alunos sobre a atuação do psicólogo. Pode-se identificar que houve predominância (46\%) nos aspectos como diálogo e fornecimento de orientação e auxílio como características principais da ação do psicólogo na escola.

Tabela 2. Distribuição das categorias de respostas dos alunos de $5^{a}$ a $8^{\mathrm{a}}$ séries sobre o papel do psicólogo na escola

\begin{tabular}{lcc}
\hline Categorias de respostas & N & \% \\
\hline Desvio de função & 15 & 14 \\
Orienta, ajuda e conversa & 50 & 46 \\
Avaliação positiva & 17 & 16 \\
Avaliação negativa & 8 & 7 \\
Muda comportamentos & 5 & 5 \\
Não sabe & 13 & 12 \\
\hline Total & 108 & 100 \\
\hline
\end{tabular}

Fonte: Elaboração dos autores

A visão sobre o psicólogo dos alunos de $5^{\mathrm{a}}$ a $8^{\mathrm{a}}$ séries pode ser interpretada como difusa. Não existe uma única caracterização desse profissional. Contudo, nota-se que em $16 \%$ das manifestações a avaliação deste profissional foi positiva e em $7 \%$ negativa.

As considerações sobre o profissional como médico de loucos representaram $15 \%$ das respostas, isto talvez indicando uma confusão que os alunos fazem entre o profissional de psicologia e o médico psiquiatra.

A respeito das críticas à atuação do psicólogo, alguns alunos reclamam que ele só faz perguntas e não faz nada. Esta compreensão possivelmente está relacionada à falta de visibilidade dos resultados e da expectativa dos alunos e da própria escola de que o psicólogo realize mudanças imediatas neste contexto. Torna-se importante ressaltar que o psicólogo está inserido em uma dinâmica social complexa e que as alterações nas relações sociais não podem ser efetuadas somente por meio da atuação deste profissional, mas sim dependem de mudanças mais amplas tanto na escola como na sociedade.

Conforme destaca Martín-Baró (2000), os problemas que estão presentes no cotidiano da maioria da população e que, certamente, refletem-se no contexto escolar, não podem ser solucionados pelos psicólogos, o que não significa que este profissional não possa dar sua contribuição nesse contexto.

Por outro lado, alguns alunos manifestaram opiniões favoráveis ao trabalho do psicólogo ao afirmarem que todas as escolas deveriam ter um serviço de psicologia, pois o trabalho é muito interessante. Os alunos expressaram uma avaliação positiva sobre o papel do psicólogo, seja atuando na escola ou na sociedade de uma maneira geral, pois este 
profissional foi visto como alguém que se dispõe a ajudar mesmo sem ter problemas, ouvir e aconselhar; ensinar a ser menos violento; não brigar e ensinar os outros a se acalmar.

Guzzo (1999, 2005) já apontava que o psicólogo tem um papel fundamental na melhoria da qualidade das relações escolares, sempre visando à autonomia e ao desenvolvimento da capacidade crítica do aluno, ao mesmo tempo em que pode propiciar oportunidade de se avaliar e considerar o desenvolvimento da criança tendo em conta elementos sociais e políticos presentes na realidade onde os estudantes estão imersos.

A compreensão dos alunos sobre o psicólogo reflete as diferenças na forma de trabalho destes profissionais. Para alguns alunos, o psicólogo ajuda mesmo sem ter problema, ou seja, atua de maneira preventiva. Outros afirmam que o psicólogo só faz perguntas, sendo este considerado um profissional passivo que espera o aparecimento de conflitos, ou que, então, não se preocupa em estabelecer um diálogo com os alunos.

Muitas destas compreensões, positivas ou negativas, podem ter representado experiências distintas que estes estudantes tiveram na relação com este profissional em outros contextos ou então demonstram opiniões sobre algo que lhes é distante - a atuação do psicólogo.

Das 108 respostas que expressavam visões sobre o psicólogo, 12\% afirmavam que era difícil identificar a função do psicólogo. Alguns alunos não conhecem o trabalho do psicólogo possivelmente por este profissional estar distante do cotidiano da maioria da população brasileira. O aspecto financeiro impede muitas pessoas de terem acesso ao serviço do psicólogo, que também não está inserido na rede municipal de Educação, ao menos em Campinas, onde a atuação dos psicólogos está ligada à Secretaria de Assistência Social ou à da Saúde. Como o psicólogo não está presente no cotidiano das escolas, isto pode contribuir para a falta de clareza dos educadores sobre a prática deste profissional.

Vale destacar que a inserção do projeto "Risco à Proteção" ocorreu por intermédio da Secretaria Municipal de Educação que, embora não disponha de profissionais contratados, desenvolve seus trabalhos com alunos da graduação do estágio profissionalizante em psicologia escolar/educacional, e profissionais vinculados ao programa de pós-graduação em Psicologia da PUC - Campinas.

Para vários alunos, a atuação do referido projeto na escola pode ter representado uma oportunidade de tomar um primeiro contato com o psicólogo, uma vez que muitos não têm dinheiro para pagar um atendimento particular realizado por este profissional ou não têm acesso aos serviços públicos existentes na região. O modelo diferenciado de intervenção deste profissional no contexto educativo favorece a compreensão de seu papel e suas possibilidades e limites de ação.

A segunda questão aborda a expectativa dos alunos sobre o serviço de psicologia. A partir das informações obtidas foram identificadas cinco categorias, a saber:
1. Avaliação positiva: expectativas positivas dos alunos em relação ao serviço da psicologia, sendo em alguns casos ainda pouco especificadas. Ex: "Espero que ajude muita gente porque muitos não têm dinheiro para pagar o psicólogo", "Espero que tire nossas dúvidas".

2. Avaliação negativa: respostas que indicam a falta de expectativas ou uma avaliação de que o psicólogo não é necessário na escola. Ex: "Não espero nada", "Não precisamos disso".

3. Auxílio à escola: contribuições apontadas pelos alunos que o psicólogo pode ajudar a escola e seus diferentes agentes na resolução de problemas já existentes. Ex: "Ajudar os professores que estão nervosos", "Ajudar a não ter mais brigas".

4. Desenvolvimento de relação diferente: expectativas de o psicólogo estabelecer relações diferenciadas com os alunos, contribuindo para o desenvolvimento dos mesmos ou ainda participar dos espaços da escola. Ex: "Aprender nossa linguagem", "Participar de conselhos".

5. Realização de atividades extracurriculares: respostas que revelam as expectativas dos alunos em relação à realização de atividades diferentes daquelas desenvolvidas no currículo comum. Ex: "Fazer palestras", "Elaborar trabalho sobre a paz".

Em $61 \%$ das considerações, os estudantes de $5^{\mathrm{a}}$ à $8^{\mathrm{a}}$ série esperam que o psicólogo forneça auxílio à equipe e à escola como um todo na resolução de problemas, conforme pode ser visto na Tabela 3.

Tabela 3. Distribuição das categorias de respostas sobre expectativas dos alunos de $5^{\mathrm{a}}$ a $8^{\mathrm{a}}$ séries sobre a atuação do psicólogo na escola

\begin{tabular}{lcc}
\hline Categorias de respostas & N & $\%$ \\
\hline Avaliação positiva & 9 & 12 \\
Avaliação negativa & 2 & 3 \\
Auxílio à escola & 47 & 61 \\
$\begin{array}{l}\text { Desenvolvimento de relação } \\
\text { diferente }\end{array}$ & 11 & 14 \\
Realização de atividades & 8 & 10 \\
extracurriculares & & \\
\hline Total & 77 & 100 \\
\hline Fonte: Elaboração dos autores &
\end{tabular}

As expectativas sobre a atuação da equipe de psicologia na escola pública em questão tornaram explícita a forma como os alunos de $5^{\text {a }}$ a 8 séries percebem 0 papel do psicólogo escolar. Do total de respostas sobre as expectativas frente à atuação do serviço de psicologia, 12\% acreditam que o psicólogo pode atuar de maneira positiva na escola. De forma pouco representativa foi indicado que o psicólogo contribui para tirar nossas dúvidas, o que pode ter sido uma demonstração de que a representação do psicólogo está vinculada à noção de um profissional 
aberto ao debate sobre diversos temas como por exemplo, sexualidade e indisciplina, além de manifestações também negativas sobre o serviço de psicologia na escola (3\%): não espero nada; não precisamos disso. A forma como estes alunos se expressaram quanto às expectativas do trabalho do psicólogo na escola onde estudam pode estar relacionada à falta de conhecimento ou de interesse acerca do trabalho deste profissional ou mesmo a experiências anteriores com outros profissionais.

$14 \%$ das respostas dos alunos de $5^{\mathrm{a}}$ a $8^{\mathrm{a}}$ séries ressaltaram a existência de uma relação diferente com o psicólogo que foge aos padrões de controle presentes na dinâmica da escola. Os alunos relatam também algumas contribuições do psicólogo na tentativa de favorecer a melhoria nas relações estabelecidas na escola, como por exemplo: ajudar os professores que estão nervosos; ajudar a não ter mais brigas; ver se tem problema na escola.

Algumas compreensões sobre o papel do psicólogo parecem superar o modelo médico e individualista já criticado por vários autores como Patto (1990, 1997), Guzzo (1999), Araújo e Almeida (2005), Cruces (2005) entre outros, uma vez que os alunos esperam que esse profissional busque se comunicar mais; participar de conselhos, ou seja, de espaços coletivos e de discussão dentro da escola. Em $10 \%$ das respostas, caberia ao psicólogo realizar atividades extracurriculares, o que revela expectativas em relação ao desenvolvimento de um trabalho diferenciado, não restrito ao currículo, como por exemplo: fazer palestras; elaborar trabalho sobre a paz. Isto talvez aponte também a necessidade de que a escola promova atividades diversificadas e mais próximas da realidade vivida por esses alunos.

\section{Considerações Finais}

Os resultados obtidos no estudo indicam que os alunos desta escola de Ensino Fundamental percebem a presença do psicólogo como algo importante e necessário no contexto educacional. Em geral, os estudantes apontaram como principais funções desse profissional a conversa sobre diversos aspectos da vida e o favorecimento das relações na escola, na família e na comunidade.

Ficou evidenciado nos desenhos e escrita dos estudantes de $1^{\text {a }}$ a $4^{a}$ séries a existência de uma posição favorável ao profissional de psicologia, uma vez que ele foi visto como um profissional que fornece apoio e auxílio, atuando como um mediador e facilitador nas interações ocorridas na escola.

A visão dos alunos de $5^{\mathrm{a}}$ a $8^{\mathrm{a}}$ séries é mais crítica e aponta alguns aspectos importantes da prática do psicólogo escolar, apresentando uma avaliação positiva deste profissional e o destaque da importância de sua atuação na resolução de conflitos e de problemas evidenciados na instituição de ensino.

Algumas expectativas dos alunos frente à atuação do psicólogo remetem à idéia de que este profissional exerça sua atividade e produza mudanças no cotidiano escolar.
Contudo, cabe frisar que isto somente pode ser concretizado por meio do trabalho coletivo com os diferentes segmentos da escola, a partir de uma visão crítica sobre as diferentes dimensões (sociais, políticas, econômicas) da realidade que permeiam a ação educativa.

Além disso, os resultados indicaram que os alunos não dispõem de informações mais detalhadas sobre o papel do psicólogo escolar, embora a equipe de psicologia estivesse inserida há três anos na escola. Deste modo, torna-se necessária uma maior divulgação a respeito da prática profissional, focalizando também a perspectiva de prevenção, que vai além da visão remediativa de intervenção psicológica.

O conhecimento sobre a visão que estudantes têm do papel do psicólogo escolar é relevante na medida em que pode fornecer indícios para o profissional redimensionar sua prática, voltando suas ações às reais demandas da comunidade em que está inserido, bem como pode subsidiar discussões acerca da formação do psicólogo que atua nessa especialidade.

Em síntese, nota-se que as expectativas dos alunos em relação à atuação do psicólogo na escola demandam uma reflexão a respeito da intervenção destes profissionais em contextos escolares. Os alunos anseiam por um profissional dinâmico, que participe ativamente do cotidiano da escola, que converse e oriente os alunos, mas que também não se detenha a uma atuação clínica e focada nos indivíduos, ou seja, um trabalho estendido a todos os agentes da instituição e que exerça um impacto nesta comunidade como um todo.

\section{Referências}

Almeida, S. F. (2003). (Org.). Psicologia escolar: éticas e competências na formação e atuação profissional. Campinas, SP: Alínea.

Araujo, C. M. M., \& Almeida, S. F. C. de. (2005). Psicologia Escolar: construção e consolidação da identidade profissional. Campinas, SP: Alínea.

Caetano, M. C. (1992). A representação de pais de alunos sobre a atuação do psicólogo na escola. Dissertação de Mestrado, Pontifícia Universidade Católica de São Paulo, São Paulo.

Cruces, A. V. (2005). Práticas emergentes em psicologia escolar: nova ética, novos compromissos. Em A. M. Martinez (Org.), Psicologia escolar e compromisso social (pp.47-65). Campinas, SP: Alínea.

Del Prette, Z. A. (1999). Psicologia, educação e LDB: novos desafios para velhas questões?. Em R. S. Guzzo (Org.), Psicologia Escolar: LDB e educação hoje (pp.11-34). Campinas, SP: Alínea.

Escudero, R., Martinez, A., Sawaya, S., Duarte, A., \& Campos, L. (1996). O papel do psicólogo escolar: opiniões de professoras. Anais do III Congresso Nacional de Psicologia Escolar (pp. 189193). Rio de Janeiro: ABRAPEE.

Freire, P. (1973). Uma educação para a liberdade. Porto: Escorpião.

Freire, P. (1989). Pedagogia do oprimido. Rio de janeiro: Paz e Terra.

Freire, P. (2006). Ação cultural e conscientização. Em P. Freire, Ação cultural para a liberdade e outros escritos. São Paulo: Paz e Terra. 
Guzzo, R. S. (1999). Novo paradigma para a formação e atuação do psicólogo escolar no cenário educacional brasileiro. Em R. S. Guzzo (Org.), Psicologia Escolar: LDB e educação hoje (pp.131144). Campinas, SP: Alínea.

Guzzo, R. S. (2005). Escola amordaçada: compromisso do psicólogo com este contexto. Em A. M. Martinez (Org.), Psicologia escolar e compromisso social (pp.17-29). Campinas, SP: Alínea.

Guzzo, R., Martínez, A., \& Campos, H. (2007). School psychology in Brazil. Em S. Jimerson, T. Oakland, \& P. Farrell (Eds.), The handbook of international school psychology. Thousand Oaks: Sage Publications.

Guzzo, R. S., \& Wechsler, S. (1993). O psicólogo escolar no Brasil: padrões, práticas e perspectivas. Em R. S. L. Guzzo, L. Almeida, \& S. Wechsler (Orgs.), Psicologia escolar: padrões e práticas em países de língua espanhola e portuguesa (pp. 39-46). Campinas, SP: Átomo.

Jacques, M. G. (1993). Um método dialético de análise de conteúdo. Psico, 24 (2), 117-127.

Martin-Baró, I. (1997). O papel do psicólogo. Estudos de Psicologia, 2(1), 7-27.

Martín-Baró, I. (1998). El fatalismo como identidad cognitiva. Em A. Blanco (Ed.), Psicología de la liberación (pp.39-130). Madri: Trota.

Martín-Baró, I. (2000). Las estructuras sociales y su impacto psicológico. Em I. Martín-Baró (Ed.), Acción y ideologia: Psicologia social desde Centroamérica (pp. 71-111). San Salvador: UCA Editores.

Neves, W. (1989). O psicólogo escolar da prefeitura Municipal de São Paulo: atividade e representação. Dissertação de Mestrado, Pontifícia Universidade Católica de São Paulo, São Paulo.

Oakland, T., \& Sternberg, A. (1993). Psicologia escolar: uma visão internacional. Em R. S. Guzzo, L. Almeida, \& S. Wechsler (Orgs.), Psicologia escolar: padrões e práticas em países de língua espanhola e portuguesa (pp. 13-28). Campinas, SP: Átomo.
Patto, M. H. S. (1984). Psicologia e ideologia: uma introdução crítica à psicologia. São Paulo: T. A. Queiroz.

Patto, M. H. S. (1990). A produção do fracasso escolar: histórias de submissão e rebeldia. São Paulo: T. A. Queiroz.

Patto, M. H. S. (1993). O conceito de cotidianidade em Agnes Heller e a pesquisa em Educação. Perspectivas, 16, 119-141.

Patto, M. H S. (1997) Para uma crítica da razão psicométrica.

Revista Psicologia USP, 8(1), 47-62.

Ribeiro, P. R., \& Guzzo, R. S. (1987). Afinal, o que pode fazer o psicólogo escolar? Estudos de Psicologia, 2(4), 89-93.

Rossi, G. (1996). Psicólogo escolar: atuação na opinião de professores e diretores de escolas públicas. Dissertação de Mestrado, Pontifícia Universidade Católica de Campinas, Campinas, São Paulo.

Senna, S., \& Almeida, S. (2005). Formação e atuação do psicólogo escolar da rede pública de ensino do Distrito Federal: panorama atual e perspectivas futuras. Em A. M. Martinez (Org.), Psicologia escolar e compromisso social (pp.119-230). Campinas, SP: Alínea.

Silva, M. B. (1995). A representação social da psicologia escolar na cidade de Curitiba: a perspectiva leiga. Anais de XVII International School Psychology Colloquium/ II Congresso Nacional de Psicologia Escolar (pp. 258-264). Campinas, SP: ABRAPEE.

Tanamachi, E., Proença, M., \& Rocha, M. (2000). Psicologia e educação: desafios teórico-práticos. São Paulo: Casa do Psicólogo.

Witter, G. P (1999). Psicólogo escolar no ensino superior e a Lei de Diretrizes e Bases. Em R. S. Guzzo (Org.), Psicologia Escolar: LDB e educação hoje (pp.103-130). Campinas, SP: Alínea.
Recebido em: 16/10/2007

Reformulado em: 01/07/2009

Aprovado em: 17/07/2009

\section{Sobre os autores}

\section{Izabella Mendes Sant'Ana}

Doutoranda em Psicologia na PUC Campinas

Antonio Euzébios Filho

Mestrando em Psicologia na PUC Campinas

Fernando Lacerda Junior

Doutorando em Psicologia na PUC Campinas

Raquel Souza Lobo Guzzo

Professora Titular da Pontifícia Universidade Católica de Campinas.

\section{Agradecimentos}

Agradecemos a colaboração das estagiárias Michelle Sampaio e Cinthia Moretti na coleta de informações.

Financiado pelo CNPq. 